\title{
Study Conduct
}

National Cancer Institute

\section{Source}

National Cancer Institute. Study Conduct. NCI Thesaurus. Code C153144.

An ongoing and/or past performance of a formal investigation as specified in a study protocol. 